\title{
Selective photooxidation of ortho-substituted benzyl alcohols and the catalytic role of ortho-methoxybenzaldehyde
}

\author{
Gabriele Scandura ${ }^{\mathrm{a}}$, Giovanni Palmisano ${ }^{\mathrm{a}}$, Sedat Yurdakal ${ }^{\mathrm{b}, *}$, Bilge Sina Tek ${ }^{\mathrm{b}}$, \\ Levent Özcan ${ }^{\mathrm{c}}$, Vittorio Loddo $^{\mathrm{d}}$, Vincenzo Augugliaro ${ }^{\mathrm{d}}$ \\ a Department of Chemical and Environmental Engineering, Institute Center for Water and Environment (iWater), Masdar Institute of Science and Technology, \\ P.O. BOX 54224, Abu Dhabi, UAE \\ ${ }^{\mathrm{b}}$ Kimya Bölümü, Fen-Edebiyat Fakültesi, Afyon Kocatepe Üniversitesi, Ahmet Necdet Sezer Kampüsü, 03200 Afyonkarahisar, Turkey \\ c Biyomedikal Mühendisliği Bölümü, Mühendislik Fakültesi, Afyon Kocatepe Üniversitesi, Ahmet Necdet Sezer Kampüsü, 03200 Afyonkarahisar, Turkey \\ d “Schiavello-Grillone" Photocatalysis Group, DEIM, Università degli Studi di Palermo, Viale delle Scienze, 90128 Palermo, Italy
}

\section{A R T I C L E I N F O}

\section{Article history:}

Received 13 May 2016

Received in revised form 26 May 2016

Accepted 28 May 2016

Available online 29 May 2016

\section{Keywords:}

Homogeneous photocatalysis

Autocatalytic photooxidation

2-Methoxybenzaldehyde

Benzyl alcohols

\begin{abstract}
A B S T R A C T
It has been recently reported by Palmisano et al. (2015) [1] that the oxidation of 2-methoxybenzyl alcohol (2-MBA) to 2-methoxybenzaldehyde (2-MBAD) proceeds in water under near-UV light with an unexpected catalytic effect of 2-MBAD. In order to investigate the catalytic role of aldehyde in photolytic oxidation of ortho-substituted benzyl alcohols (OSBAs), reactivity runs were carried out with 2methylbenzyl alcohol (2-MeBA), 2-nitrobenzyl alcohol (2-NBA), 2-hydroxybenzyl alcohol (2-HBA) and 2chlorobenzyl alcohol (2-ClBA) in the absence and in the presence of their corresponding aldehyde. None of those alcohols showed a measurable oxidation rate even in the presence of their aldehydes but 2-NBA was oxidised very fast, although no corresponding carbonyl product was obtained. The possible catalytic role of 2-MBAD was investigated for the photolytic oxidation of 4-methoxybenzyl alcohol (4-MBA), 4nitrobenzyl alcohol (4-NBA), 2-ClBA, 2-HBA, 2-MeBA and ferulic acid (FA). The results showed that 2MBAD acts as a catalyst only for 4-MBA, 2-HBA and FA. The photocatalytic oxidation of OSBAs in the presence of powdered $\mathrm{TiO}_{2}$ has been also carried out in order to investigate the mutual influences, if any, between homogeneous and heterogeneous processes. The reactivity runs were carried out with $\mathrm{TiO}_{2}$ photocatalyst in water and under near-UV irradiation; a home-prepared (HP) $\mathrm{TiO}_{2}$ sample was used along with Degussa P25. HP catalyst showed the best performance: the 2-MBA half-life time was 5 times smaller and the selectivity to aldehyde 13 times higher than in the presence of Degussa P25.
\end{abstract}

( 2016 Elsevier B.V. All rights reserved.

\section{Introduction}

Heterogeneous photocatalysis publications works generally refer to waste water treatment to degrade harmful compounds such as pesticides, dyes, drugs, and their intermediates [2,3]. Photocatalytic reactions involve fast attacks of strong oxidizing agents, mainly hydroxyl radicals, which unselectively degrade and mineralize almost all organic compounds especially in water [4,5]. However, photocatalysis is capable also of selective oxidation and reduction to produce high value chemicals from a number of substrates [6-8].

Examples of selective heterogeneous photocatalytic reactions are the syntheses of cyclic amino acids [9], cyclohexanol and

\footnotetext{
* Corresponding author.

E-mail address: sedatyurdakal@gmail.com (S. Yurdakal).
}

cyclohexanone [10], imines [11], 1- and 2-adamantanol and adamantanone [12], and some heterocyclic and aromatic aldehydes [7,13].

Homogeneous photocatalysis has been also deeply investigated during the last decades for carrying out reactions such as water splitting, degradation of harmful contaminants and organic syntheses [14-20]. On the last field, however, a limited number of studies on the selective oxidation of alcohols has been done, although this photoreaction has been deeply investigated in heterogeneous systems containing $\mathrm{TiO}_{2}$-based catalysts [13,21-23].

Homogeneous systems, such as ruthenium complexes [24] or ferric ions [25-27], have been used as photocatalysts too. Chen et al. [24] reported that the photocatalytic oxidation of aliphatic and aromatic alcohols under sun light in water at ambient conditions produces aldehydes and ketones with high selectivity by using a chromophore-catalyst dyad assembly of ruthenium 
polypyridyl complexes. Spasiano et al. [25] carried out the photosynthesis of benzaldehyde from benzyl alcohol in water by using $\mathrm{Fe}(\mathrm{III})$ aquo-complex as photocatalyst at very low $\mathrm{pH}(0.5)$ and high yield values in aldehyde were obtained. Benzyl alcohol was also oxidised to benzaldehyde under visible light irradiation by using homogeneous $\mathrm{CuCl}_{2}$ /solvent as catalyst and molecular oxygen as oxidant [28]. The obtained results showed that the formation of a visible light responsive complex between $\mathrm{Cu}(\mathrm{II})$ and the solvent is responsible for the benzyl alcohol partial oxidation; molecular oxygen is not incorporated into benzaldehyde and it is only involved in the $\mathrm{Cu}(\mathrm{I})$ oxidation into $\mathrm{Cu}(\mathrm{II})$, serving as a terminal hydrogen acceptor to form $\mathrm{H}_{2} \mathrm{O}$.

Selective photolytic and photocatalytic reactions could offer alternative green routes to organic syntheses that currently are carried out under environmentally unfriendly conditions: high temperature and pressure, and the use of dangerous reactants and organic solvents $[7,21]$.

A recent publication [1] reported an unexpected autocatalytic photooxidation of 2-methoxybenzyl alcohol (2-MBA) in water, under UV light and without any catalyst. The main oxidation product was the corresponding aldehyde, 2-methoxybenzaldehyde (2-MBAD), which also had the role of catalyst. The highest selectivity for 2-MBAD production from 4-MBA oxidation in the presence of $20 \% \mathrm{O}_{2}$ (air) was $85 \%$ for $70 \%$ conversion (64\% yield). Indeed, it has been showed that, only in presence of oxygen and 2-MBAD, such reaction takes place at a measurable rate. The effect of the concentration of dissolved oxygen in water was also investigated: the molecular oxygen affects the reaction rate in an ambivalent role that has never been seen in analogous photooxidations of aromatic alcohols. Oxygen is in fact necessary for the reaction to take place, but it is detrimental in high concentrations due to its quenching role. In the same study [1] other aromatic alcohols, in addition to 2-MBA, were also tested for a preliminary investigation on the correlation between structural features and autocatalytic behaviour of their corresponding aldehyde. Thus, benzyl alcohol, 3-methoxybenzyl alcohol, 4-methoxybenzyl alcohol, 2,4-dimethoxybenzyl alcohol, and 2,3,4-trimethoxybenzyl alcohol were tested by following the same procedure used for 2-MBA; only for 2,4-dimethoxybenzyl alcohol, the corresponding aldehyde showed a similar behaviour to that observed for 2-MBAD in the 2-MBA oxidation.

The present study has been devoted to understand if the photoreactivity features observed with the 2-MBA could be extended to other ortho-substituted benzyl alcohols (OSBAs). To this aim, 2-methylbenzyl alcohol (2-MeBA), 2-hydroxybenzyl alcohol (2-HBA), 2-chlorobenzyl alcohol (2-ClBA), and 2-nitrobenzyl alcohol (2-NBA) have been tested for photooxidation in homogeneous phase in the presence of their corresponding aldehydes. Moreover, the possible role of 2-MBAD as homogeneous catalyst has been studied in the oxidation of 4-methoxybenzyl alcohol (4-MBA), 4-nitrobenzyl alcohol (4-NBA), 2-ClBA, 2-HBA, 2-MeBA and ferulic acid (FA). Finally, in order to investigate likely influences between homogeneous and heterogeneous photocatalytic systems, the OSBAs have been photooxidized in aqueous suspensions containing powdered commercial and home-prepared $\mathrm{TiO}_{2}$. Hereafter, the aldehydes corresponding to the OSBAs are indicated as follows: 2-methylbenzaldehyde (2-MeBAD), 2-hydroxybenzaldehyde (2-HBAD), 2-chlorobenzaldehyde (2-ClBAD), and 2-nitrobenzaldehyde (2-NBAD).

\section{Experimental}

\subsection{Catalyst preparation}

The experimental details of home-prepared $\mathrm{TiO}_{2}$ have been reported elsewhere [26]. The precursor solution was obtained by adding $20 \mathrm{~mL}$ of $\mathrm{TiCl}_{4}$ (purity $>97 \%$, Fluka) dropwise under magnetic stirring to $200 \mathrm{~mL}$ of deionized water contained in a $500 \mathrm{~mL}$ beaker placed inside an ice bath. After that, the beaker was sealed and mixing was prolonged for $12 \mathrm{~h}$ at room temperature, eventually obtaining a clear solution. $125 \mathrm{~mL}$ of the resulting solution was poured inside a $250 \mathrm{~mL}$ round-bottomed flask fitted with a Graham condenser. The flask was heated at $373 \mathrm{~K}$, magnetically stirred, and refluxed for $2 \mathrm{~h}$; the reflux zero time has been taken as that for which the solution left its transparency. The obtained suspension was then dried at $323 \mathrm{~K}$ by means of a rotary evaporator machine (Buchi, model $\mathrm{M}$ ) working at $100 \mathrm{rpm}$ in order to obtain the final powdered catalysts. The so prepared catalyst is hereafter indicated as HP.

Previous characterizations of HP and Degussa P25 $\mathrm{TiO}_{2}[29,30]$ showed that HP catalyst is constituted by anatase (ca. $4 \%$ ), rutile (ca. 1.4\%) and amorphous phases (ca. 95\%) while, for the commercial one, these percentages are 72,18 and $10 \%$, respectively. BET surface areas of Degussa P25 and HP are $50 \mathrm{~m}^{2} / \mathrm{g}$ and $226 \mathrm{~m}^{2} / \mathrm{g}$, respectively; primary and secondary particle sizes of HP are 3-7 nm and $25 \mathrm{~nm}$ and those of P25 are 30 and $80 \mathrm{~nm}$, respectively.

\subsection{Reaction system a (annular photoreactor)}

A Pyrex batch home-made photoreactor of cylindrical shape (internal diameter: $100 \mathrm{~mm}$; height: $126 \mathrm{~mm}$ ) was used for carrying out reactivity runs in homogeneous and heterogeneous regimes with the following substrates: 2-methylbenzyl alcohol (2-MeBA), 2-hydroxybenzyl alcohol (2-HBA), 2-chlorobenzyl alcohol (2-ClBA) and 2-nitrobenzyl alcohol (2-NBA). For the sake of comparison the previously investigated 2-methoxybenzyl alcohol (2-MBA) [1] was also tested. The reacting system set up is reported in Fig. S1; the photoreactor was supplied with ports in its upper section for the inlet and outlet of gases and for sampling. The aqueous solution or suspension (volume of $800 \mathrm{~mL}$ ) was magnetically stirred and an $\mathrm{O}_{2} / \mathrm{N}_{2}$ mixture with different $\mathrm{O}_{2}$ concentrations was bubbled inside. These mixtures were set by means of a Bronkhorst high-tech mass flow controller. The bubbling started $30 \mathrm{~min}$ before switching the lamp on and it was maintained during all the runs. The dissolved $\mathrm{O}_{2}$ concentration was measured before starting the irradiation by using an HD22559.2 apparatus (Delta Ohm). When pure oxygen was bubbled, the measured concentration in water was $1.2 \mathrm{mM}$; this figure linearly decreased with the decrease of $\mathrm{O}_{2}$ percentage in the bubbled mixture as expected by Henry's law. A $125 \mathrm{~W}$ medium pressure Hg lamp (Helios Italquartz, Italy; its spectrum is shown in Fig. S2) was axially positioned inside the photoreactor and it was cooled by water circulating through a Pyrex thimble (external diameter: $36 \mathrm{~mm}$ ). The radiation energy impinging on the solution or suspension had an average value of $4.4 \mathrm{~mW} \cdot \mathrm{cm}^{-2}$; it was measured between 315 and $400 \mathrm{~nm}$ by using a radiometer (Delta Ohm, DO 9721). During the photoreactivity runs the aqueous solution or suspension reached the temperature of ca. $300 \mathrm{~K}$. For all the runs the initial alcohol concentration was $0.5 \mathrm{mM}$; when the ortho-substituted benzaldehyde (OSBAD) corresponding to the tested alcohol was added to the solution, its concentration was $0.165 \mathrm{mM}$.

For the heterogeneous runs, commercial $\mathrm{TiO}_{2}$ (Degussa P25) and $\mathrm{HP} \mathrm{TiO}_{2}$ were used in suspension at the same experimental conditions used for the homogeneous runs. The amount of both catalysts was chosen in such a way that the resulting suspension could transmit only $10 \%$ of the total irradiation measured at the outer wall of photoreactor in the presence of only water. This strategy guaranteed that all the catalyst particles were irradiated.

During the photoreactivity runs, samples were withdrawn at fixed times. In the case of heterogeneous runs these samples were immediately filtered through a $0.45 \mu \mathrm{m}$ hydrophilic membrane 
(HA, Millipore) before being analyzed. The identification and quantitative determination of alcohols concentrations and their oxidation products were performed by means of a Beckman Coulter HPLC (System Gold 126 Solvent Module and 168 Diode Array Detector), equipped with a Phenomenex Kinetex $5 \mu \mathrm{m} \mathrm{C18}$ 100 column $(150 \mathrm{~mm}$ long $\times 4.6 \mathrm{~mm}$ id $)$ at $298 \mathrm{~K}$. The eluent consisted of a mixture of acetonitrile and $13 \mathrm{mM}$ trifluoroacetic acid aqueous solution (20:80 v:v), its flow rate was $0.80 \mathrm{~mL} \mathrm{~min}^{-1}$ Species were identified by comparing their retention times and UV-vis spectra with those of Sigma-Aldrich standards. All the used chemicals were purchased from Sigma-Aldrich and used without any further purification.

Table 1

Acronyms and structural formulas of used substrates and their corresponding aldehydes.

\begin{tabular}{|c|c|c|c|}
\hline Substrate acronym & Structural formula of substrate & Aldehyde acronym & Structural formula of aldehyde \\
\hline 2-MBA & & 2-MBAD & \\
\hline
\end{tabular}

2-MeBA<smiles>Cc1ccccc1CO</smiles>

2-NBA<smiles>O=[N+]([O-])c1ccccc1CO</smiles>

2-HBA<smiles>OCc1ccccc1O</smiles>

2-CIBA<smiles>OCc1ccccc1Cl</smiles><smiles>COc1ccc(CO)cc1</smiles>

4-NBA<smiles>O=[N+]([O-])c1ccc(CO)cc1</smiles>

FA<smiles>COc1cc(/C=C/C(=O)O)ccc1O</smiles>

2-ClBAD<smiles>O=Cc1ccccc1Cl</smiles>

4-MBAD

2-MeBAD<smiles>Cc1ccccc1C=O</smiles>

2-NBAD<smiles>O=Cc1ccccc1[N+](=O)[O-]</smiles>

2-HBAD<smiles>O=Cc1ccccc1O</smiles><smiles>COc1ccc(C=O)cc1</smiles>

4-NBAD<smiles>O=Cc1ccc([N+](=O)[O-])cc1</smiles>

Vanilin<smiles>C=Cc1ccc(O)c(OC)c1</smiles> 


\subsection{Reaction system $B$ (Beaker irradiated from the top by fluorescent} lamps)

In order to study the catalytic effect, if any, of the 2-MBAD towards the photooxidation of the following substrates (4-methoxybenzyl alcohol (4-MBA), 4-nitrobenzyl alcohol (4-NBA), ferulic acid (FA), 2-ClBA, 2-HBA, and 2-MeBA), another batch photoreactor was used; its picture is reported in Fig. S3. This photoreactor allowed carrying out very quick and reliable reactivity runs. The photoreactor was a beaker of $250 \mathrm{~mL}$ and it contained $150 \mathrm{~mL}$ of aqueous solution with a substrate initial concentration equal to $0.5 \mathrm{mM}$; the solution was mixed by a magnetic stirrer. The reactor was irradiated by 4 fluorescent lamps (Philips, 8W) placed on top of it at $68 \mathrm{~mm}$ far away from the free surface of the solution; each lamp emitted a monochromatic radiation at $365 \mathrm{~nm}$ and the radiation energy impinging on the solution had an average value of $1.45 \mathrm{~mW} \mathrm{~cm}^{-2}$ measured between 315 and $400 \mathrm{~nm}$ by a Delta Ohm 9721 radiometer. The solution was in contact with the atmosphere so that the dissolved oxygen concentration was that inequilibrium with air. Each substrate was tested alone or by adding 2-MBAD whose initial concentration was $0.17 \mathrm{mM}$.

The run procedure and the analytical technique were the same ones used for the reaction system $A$.

\section{Results and discussion}

The acronyms and structural formulas of all the tested alcohols and their corresponding aldehydes are given in Table 1.

\subsection{Homogeneous photooxidation}

As previously reported [1] the 2-MBA photooxidation in water occurred under near-UV light and the produced aldehyde showed to promote the reaction rate in the presence of a limited concentration of dissolved oxygen - specifically, bubbling a nitrogen/oxygen mixture containing less than $2 \%$ of oxygen. Oxygen was found to be essential for the occurrence of 2-MBA photoconversion. However, an excess of oxygen concentration inhibited the reaction, giving rise to a quenching effect that interestingly - could be compensated by increasing the initial concentration of 2-MBAD. A reaction mechanism was suggested by considering the involvement of methoxy substituent in 2-MBA direct oxidation and the ambivalent role of molecular oxygen which acted as both oxidant and quencher of the excited state of MBAD [1].

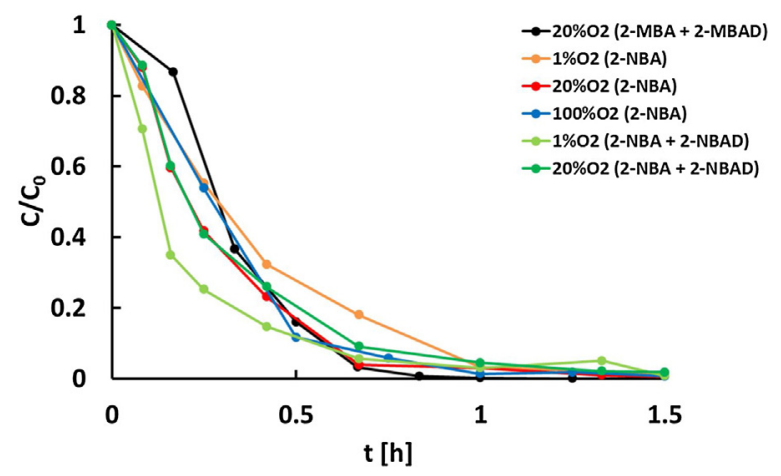

Fig. 1. Degradation of 2-NBA or 2-MBA vs irradiation time in runs at different concentration of $\mathrm{O}_{2}$. Alcohol initial concentration, $\mathrm{C}_{0}=0.5 \mathrm{mM}$. The black and the green curves are representing to the runs in presence of 2-NBAD. (For interpretation of the references to colour in this figure legend, the reader is referred to the web version of this article.).

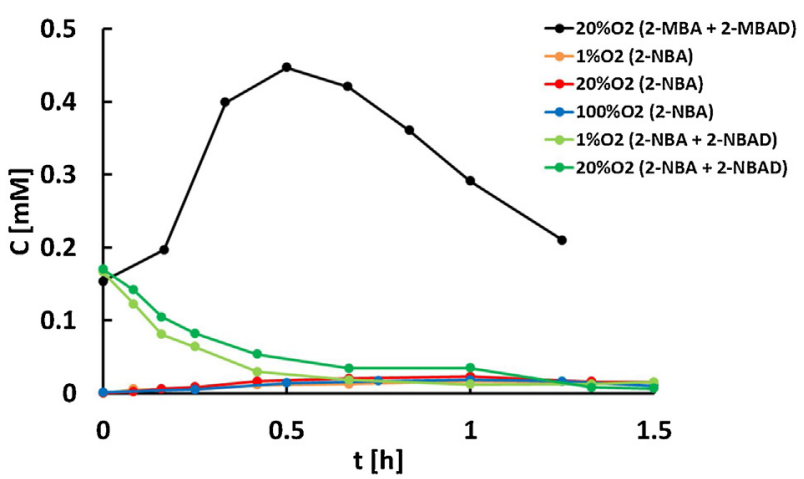

Fig. 2. 2-NBAD or 2-MBAD concentration vs irradiation time related to the runs reported in Fig. 1.

Figs. 1 and 2 show the reactivity results obtained by testing 2-NBA. This alcohol was considerably oxidised, independently of oxygen concentration; on the contrary, the results obtained with the other OSBAs showed that their photooxidation was negligible even when the corresponding OSBAD was added to the reaction system. For 2-NBA in the presence of $20 \% \mathrm{O}_{2}$ inlet gas the reaction rate seemed to be weakly affected by the addition of 2-NBAD (see Figs. 1 and 2). In these conditions, in fact, 2-NBA oxidation rate did not change with respect to that observed without 2-NBAD. The rate, indeed, increased when a much lower $\mathrm{O}_{2}$ concentration (1\%) was used. This fact should suggest that the aldehyde is able to affect the 2-NBA oxidation process only when the $\mathrm{O}_{2}$ concentration is low. The disappearance patterns of 2-NBA and 2-MBA were quite similar when $20 \% \mathrm{O}_{2}$ was bubbled into the system, but the aldehyde did not produce any autocatalytic effect in the case of the nitro substituent group. Finally, the selectivity to 2-NBAD is less than $5 \%$ at a conversion of $50 \%$; this detrimental effect given by the nitro group on the selectivity to aldehyde was previously reported in the case of heterogeneous photocatalytic oxidations [13].

By considering the UV absorption spectra of the OSBAs and OSBADs and the irradiance spectrum of the lamp (see Figs. S4-S8), it may be noted that 2-HBA, 2-MeBA, 2-ClBA do not absorb above $300 \mathrm{~nm}$ (it should be highlighted that Pyrex thimble glass cut about $99 \%$ and $60 \%$ of the incident radiation in the $200-280 \mathrm{~nm}$ and $280-$ $315 \mathrm{~nm}$ ranges, respectively). On the contrary, 2-NBA absorbs in the 300-360 nm range and this could justify the disappearance of this alcohol under UV radiation and in the presence of dissolved oxygen. All OSBADs spectra highlight absorption bands in the near ultraviolet region (300-400 $\mathrm{nm}$ ) but this feature, of course, does not imply that they actually react. In fact the runs in which the activity of 2-MeBAD and 2-ClBAD was tested showed that the aldehyde concentration did not change; on the contrary 2-NBAD was photo-oxidised during the photocatalytic runs of 2-NBA degradation. In addition, the 2-HBAD concentration remained constant during the runs of 2-HBA photooxidation, although it has a UV absorption spectrum similar to that of 2-MBAD.

The reactivity results clearly indicate that the $-\mathrm{OCH}_{3}$ group is essential to get the autocatalytic effect independently of its electron-donor properties, since even in the case of hydroxyl group substituent (a much more electron donor group than methoxy one) no reactivity has been observed.

To explain the reactivity results obtained when 2-MBAD was added to the dissolved 4-MBA, 4-NBA, FA, 2-ClBA, 2-HBA, and 2-MeBA, it is useful to recall the proposed mechanism by which 2-MBAD catalyzes 2-MBA oxidation [1]. Under UV irradiation the aldehyde carbonyl yields an excited singlet state that develops via intersystem crossing to the excited triplet state. The latter reacts with the benzylic hydrogen of the alcohol to generate two ketyl radicals, which in turn can evolve into other oxidation products, as 
Table 2

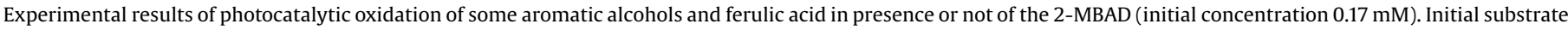
concentration: $0.5 \mathrm{mM}$. Note: irradiation time, $\mathrm{t}$; substrate conversion, $\mathrm{X} ; 2$ 2-MBAD conversion, $\mathrm{X}_{\mathrm{MBAD}}$; selectivity to the corresponding aldehyde, $\mathrm{S}$.

\begin{tabular}{|c|c|c|c|c|c|}
\hline \multirow[b]{2}{*}{ Substrate } & \multirow{2}{*}{$\begin{array}{l}\text { Without 2-MBAD } \\
\mathrm{X} \text { after } 3 \mathrm{~h}[\%]\end{array}$} & \multicolumn{4}{|c|}{ In the presence of 2-MBAD } \\
\hline & & $\mathrm{t}_{\mathrm{X}=50 \%}[\mathrm{~min}]$ & $\mathrm{S}_{\mathrm{X}=50}[\%]$ & $\mathrm{X}$ after $3 \mathrm{~h}[\%]$ & $\mathrm{X}_{2 \text {-MBAD }}$ after $3 \mathrm{~h}[\%]$ \\
\hline 4-MBA & 0 & 12 & 100 & 100 & \\
\hline FA & 0 & 30 & 1.6 & 99 & \\
\hline 2-HBA & 0 & 180 & 0.6 & 50 & 33 \\
\hline 4-NBA & 5.1 & - & 11.4 & 10.4 & 99 \\
\hline $2-\mathrm{CBA}$ & 0 & - & - & 1.5 & 14 \\
\hline 2-MeBA & 0 & - & 8 & 2 & 22 \\
\hline
\end{tabular}

also into the same aldehyde (detailed reaction schemes can be found in Ref. [1]). Now, by observing the results reported in Table 2 , it can be asserted that the excited triplet state of the 2-MBAD interacts significantly with aromatic species bearing strongly activating electron donor group (4-MBA, FA, 2-HBA) whereas it has an almost negligible effect when a weakly activating group (2-MeBA) or an electron withdrawing group (4-NBA, 2-ClBA) are present in the aromatic ring.

Nevertheless, a selectivity towards the corresponding aldehyde equal to $100 \%$ in the case of $4-\mathrm{MBA}$ against a figure of about $1 \%$ when the substrate is 2-HBA suggests the hypothesis (to be investigated in the future) that the evolution of the ketyl radical follows two different paths.

\subsection{Heterogeneous photooxidation}

Since only 2-MBA among the investigated OSBAs displayed an autocatalytic photooxidation in homogeneous phase, the heterogeneous reactivity runs were mainly focused on this one. It is important to outline that the reactivity results obtained in the presence of solid catalyst are affected not only by the features of the heterogeneous photocatalytic process, but also by those of the homogeneous photoassisted process [21]. These effects may be conflicting. In fact, in the heterogeneous system, a higher concentration of dissolved molecular oxygen produces a beneficial effect as the reaction rate increases; at the same time, however, for the homogeneous photochemical process the oxygen plays a double role: beneficial, as 2-MBA oxidant, but also detrimental, as 2-MBAD excited state quencher. Indeed, the oxygen molecules promote the photooxidation via a heterogeneous path and, hence, the induction time, observed in homogeneous runs and due to the quenching phenomena, vanishes. In addition, the autocatalytic effect played by the aldehyde is less relevant, especially at mid to high concentration of $\mathrm{O}_{2}$. Another effect to be taken into account is that the powder has a shading effect on the incoming light radiation, and consequently the homogeneous reaction rate decreases with respect to the homogeneous case.
The photoreactivity results of 2-MBA oxidation at different molar percentages of oxygen in the bubbling $\mathrm{N}_{2}-\mathrm{O}_{2}$ mixture and by using different catalysts are given in Table 3 and Figs. S9 and S10 . When P25 was used as the catalyst, the selectivity to 2-MBAD was less than $10 \%$ when the bubbled mixture contained more than $20 \%$ $\mathrm{O}_{2}$. Conversely, in the runs with $1 \%$ and $2 \%$ of $\mathrm{O}_{2}$ the autocatalytic effect was immediately visible (in other words, the induction time in the homogeneous phase runs was negligible) and, as a consequence, the selectivity was higher (around 50\% at 2\% $\mathrm{O}_{2}$ ). The shortest time to get a total conversion of the alcohol was observed when $\mathrm{O}_{2}$ was $10 \%$. In fact, in the latter case, the oxidation rate in heterogeneous phase is not the highest, but after $2 \mathrm{~h}$ the autocatalytic effect of the aldehyde speeded the reaction up (the curve in Fig. S9 changes slope).

The 'synergy' between the catalyst in suspension and the autocatalytic effect coming from the aldehyde becomes more evident by using the HP catalyst, which generally is more selective towards aromatic aldehydes [21]. As expected, the disappearance of the 2-MBA was faster with respect to the runs with P25 and the selectivities to 2-MBAD were higher than $60 \%$ independently of $\mathrm{O}_{2}$ percentage (see Table 3$)$. The lowest time $(12-16 \mathrm{~min})$ to get the alcohol complete conversion was with $\mathrm{O}_{2}$ percentage of $10-20 \%$.

The unexpected high rate of the partial oxidation, obtained with $\mathrm{HP}$, could be ascribed to the presence of amorphous $\mathrm{TiO}_{2}$ phases in the HP catalyst [30]: the homogeneous photoreaction could be, indeed, promoted by the availability of more photons than in the case of P25. This hypothesis is supported by the higher reactivity obtained with P25 when 4-MBA was oxidised, since 4-MBA does not react at all in homogeneous conditions.

Table 4 reports the reactivity results obtained from the photocatalytic runs carried out with different OSBAs in the presence of $\mathrm{P} 25$ or $\mathrm{HP}$ and $20 \% \mathrm{O}_{2}$. All the OSBAs were reactive in these conditions. Nevertheless, only 2-HBA, 2-MeBA and 2-ClBA showed a similar degradation rate in the presence of HP. It is important to remark that, in homogenous phase, 2-HBA, 2-MeBA and 2-ClBA did not react and hence, for these alcohols, a purely heterogeneous reaction path can be supposed, similarly to the

Table 3

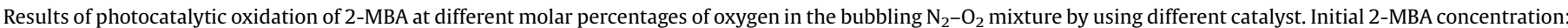
$0.5 \mathrm{mM}$. Note: irradiation time, t; 2-MBA conversion, $\mathrm{X}$; selectivity to 2-MBAD, S.

\begin{tabular}{|c|c|c|c|c|c|c|c|}
\hline Catalyst & $\mathrm{O}_{2}[\%]$ & $\mathrm{t}_{\mathrm{X}=50 \%[\mathrm{~min}]}$ & $\mathrm{t}_{\mathrm{X}=70 \%[\mathrm{~min}]}$ & $\mathrm{t}_{\mathrm{X}=90}[\mathrm{~min}]$ & $\mathrm{S}_{\mathrm{X}=50}[\%]$ & $S_{X=70}[\%]$ & $\mathrm{S}_{\mathrm{X}=90}[\%]$ \\
\hline P25 & 1 & 141 & 195 & $>240$ & 20 & 26 & - \\
\hline P25 & 2 & 97 & 118 & 145 & 45 & 49 & 48 \\
\hline P25 & 10 & 80 & 126 & 141 & 10 & 14 & 22 \\
\hline P25 & 20 & 67 & 120 & 208 & 6.8 & 4.8 & 2.9 \\
\hline P25 & 40 & 53 & 91 & 170 & 5.8 & 3.9 & 1.4 \\
\hline P25 & 100 & 47 & 86 & 158 & 7.0 & 4.7 & 1.9 \\
\hline $\mathrm{HP}$ & 1 & 33 & 48 & 67 & 74 & 66 & 58 \\
\hline $\mathrm{HP}$ & 2 & 23 & 36 & 50 & 74 & 75 & 68 \\
\hline HP & 10 & 16 & 18 & 22 & 85 & 86 & 84 \\
\hline HP & 20 & 12 & 17 & 24 & 90 & 82 & 70 \\
\hline HP & 40 & 30 & 41 & 52 & 81 & 79 & 78 \\
\hline HP & 100 & 44 & 55 & 75 & 84 & 85 & 85 \\
\hline
\end{tabular}


Table 4

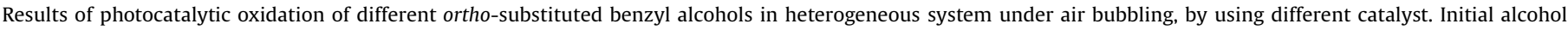

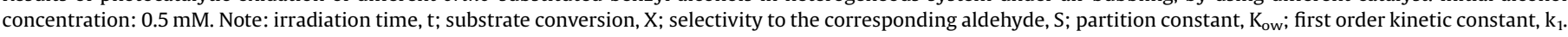

\begin{tabular}{|c|c|c|c|c|c|c|c|}
\hline \multirow[b]{2}{*}{ Substrate } & \multirow[b]{2}{*}{$\mathrm{K}_{\mathrm{ow}}$} & \multicolumn{3}{|l|}{ P25 } & \multicolumn{3}{|l|}{$\mathrm{HP}$} \\
\hline & & $\mathrm{t}_{\mathrm{X}=50 \%}[\mathrm{~min}]$ & $\mathrm{S}_{\mathrm{X}=50}[\%]$ & $\mathrm{k}_{1}\left[\mathrm{~h}^{-1}\right]$ & $\mathrm{t}_{\mathrm{x}=50 \%}[\mathrm{~min}]$ & $\mathrm{S}_{\mathrm{X}=50}[\%]$ & $\mathrm{k}_{1}\left[\mathrm{~h}^{-1}\right]$ \\
\hline 2-MBA & 1.02 & 70 & 6.8 & 0.681 & 12 & 90 & 9.57 \\
\hline 2-HBA & 0.387 & 132 & 7.5 & 0.271 & 219 & 8.0 & 0.181 \\
\hline 2-MeBA & 1.55 & 69 & 7.7 & 0.661 & 306 & 8.7 & 0.138 \\
\hline 2-ClBA & 1.82 & 120 & 9.8 & 0.346 & 390 & 18 & 0.099 \\
\hline 2-NBA & 1.22 & 11 & 4.5 & 2.799 & 13 & 2.0 & 2.372 \\
\hline
\end{tabular}

photocatalytic oxidation of benzyl alcohol and 4-methoxybenzyl alcohol [13]. The photogenerated hole extracts an electron from the alcoholic hydroxyl group and, subsequently, the formation of an aldehydic group takes place. Then, the corresponding aldehyde could undergo an attack from $\mathrm{OH}$ radicals on the aromatic ring due to the presence of an electron-withdrawing group (-CHO). The different reaction rates for 2-HBA, 2-MeBA and 2-ClBA (at the same experimental conditions) can be attributed, at least partly, to the influence of the substituent group in ortho-position. On the whole, the aromatic alcohol oxidation rate is affected by two important factors. The former is the presence of an electron donor group, hindering the molecule adsorption on the catalyst surface. The latter is the octanol-water partition constant $\left(\mathrm{K}_{\mathrm{ow}}\right)$ which indicates the ability of a chemical compound to dissolve in a non-polar solvent rather than in a polar one: namely, for higher partition constant the molecules tend to adsorb better on the catalyst, since their affinity with water is low. Summarizing, hydroxyl group is both strongly electron donor and is characterized by a low $\mathrm{K}_{\mathrm{ow}}$ (0.387); as a consequence, the oxidation rate of the 2-HBA is slower than that of the 2-MeBA.

When HP catalyst was used, the reaction rates of 2-HBA, 2-MeBA and 2-ClBA were lower than the ones obtained with P25 (see Table 4). Reactions on P25 are usually much faster than with HP and, in the presence of these three substrates, homogeneous reaction does not occur differently from the 2-MBA case.

By using P25, the OSBAs photodegradation kinetics seem to follow a first order kinetic (see Fig. S11); conversely, by using HP catalyst, 2-ClBA, 2-MeBA and 2-HBA seem to track a zero-order kinetic (see Fig. S12), whereas 2-NBA still follows a first order kinetic and for this reason all the kinetic constants reported in Table 4 have been obtained by the same least-square fitting procedure applied to the experimental data. In other words, it was decided to consider all the OSBA kinetics as first order in order to make comparisons.

The reaction rate of 2-NBA, on one other hand, does not seem to be affected by the presence of HP, neither by P25. Indeed, 2-NBA exhibited a concentration vs. time curve very similar to that obtained in the absence of catalyst (see Fig. 3 ). Thus, the hypothesis

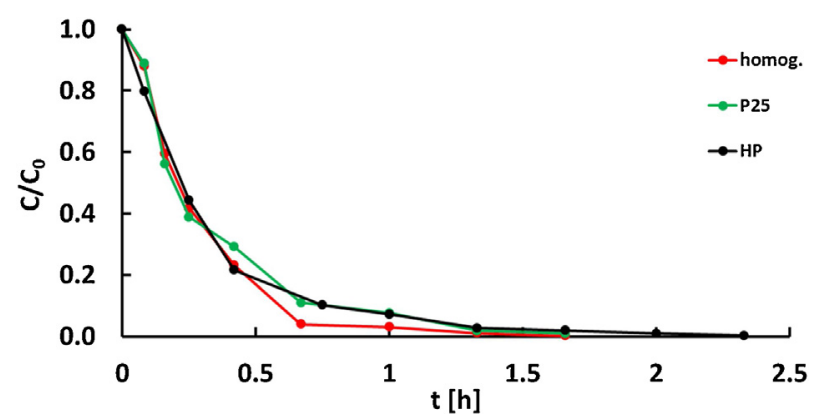

Fig. 3. Degradation of 2-NBA vs irradiation time in homogeneous conditions, with P25 and with HP. Initial 2-NBA concentration, $\mathrm{C}_{0}=0.5 \mathrm{mM} . \mathrm{O}_{2}$ concentration: $20 \%$. that, even in presence of a photocatalyst, 2-NBA is oxidised by means of a homogeneous reaction cannot be ruled out completely.

For all the OSBA, the selectivities to the corresponding OSBAD were lower than $10 \%$ with P25; with HP the selectivity to the corresponding aldehyde was low (below 20\%), except for 2-MBA as explained previously.

\section{Conclusions}

Ortho-substituted benzyl alcohols were oxidised photocatalytically in homogeneous and heterogeneous $\left(\mathrm{TiO}_{2}\right)$ conditions in water and under UVA/Vis irradiation. In homogenous phase, only 2-NBA was oxidised very fast without using its corresponding aldehyde as catalyst. Among all used substrates, 2-MBA was oxidised to 2-MBAD selectively (up to $100 \%$ ) just in the presence of a certain concentration of 2-MBAD (in the present work a concentration of $0.17 \mathrm{mM}$ was used), and at relatively low oxygen concentrations. 2-MBAD was found to act as a homogeneous oxidation catalyst under near UV radiation for some substrates, such as 4-metoxybenzyl alcohol, 2-hydroxybenzyl alcohol and ferulic acid. When a solid catalyst such as $\mathrm{TiO}_{2}$ is present in the system, the analysis of the 2-MBA reactivity results must be done by considering the contemporary occurrence of heterogeneous and homogeneous paths since this substrate may undergo oxidation both in homogeneous and heterogeneous media. These results indicate that, in order to perform 2-MBA oxidation, a photocatalyst with a low degree of crystallinity (such as HP) would be used being more photoactive than $\mathrm{P} 25$, which is - on the contrary - the most active commercial $\mathrm{TiO}_{2}$ sample for oxidation of other used benzyl alcohols.

\section{Appendix A. Supplementary data}

Supplementary data associated with this article can be found, in the online version, at http://dx.doi.org/10.1016/j. jphotochem.2016.05.022.

\section{References}

[1] G. Palmisano, G. Scandura, V. Augugliaro, V. Loddo, A. Pace, B.S. Tek, S. Yurdakal, L. Palmisano, J. Mol. Cat. A: Chem. 403 (2015) 37-42.

[2] A. Fujishima, T.N. Rao, D.A. Tryk, J. Photochem. Photobiol. C: Photochem. Rev. 1 (2000) $1-21$.

[3] V. Augugliaro, M. Bellardita, V. Loddo, G. Palmisano, L. Palmisano, S. Yurdakal, J. Photochem. Photobiol. C: Photochem. Rev. 13 (2012) 224-245.

[4] M. Schiavello, Heterogeneous Photocatalysis, Wiley, Chichester, 1997.

[5] Photocatalysis, in: N. Serpone, E. Pelizzetti (Eds.), Fundamentals and Applications, Wiley, New York, 1989.

[6] X. Lang, X. Chen, J. Zhao, Chem. Soc. Rev. 43 (2014) 473-486.

[7] V. Augugliaro, G. Camera-Roda, V. Loddo, G. Palmisano, L. Palmisano, J. Soria, S. Yurdakal, J. Phys. Chem. Lett. 6 (2015) 1968-1981.

[8] D. Spasiano, R. Marotta, S. Malato, P. Fernandez-Ibañez, I. Di Somma, Appl. Catal. B: Environ. 170 (2015) 90-123.

[9] B. Ohtani, B. Pal, S. Ikeda, Catal. Surv. Asia 7 (2003) 165-176.

[10] C.B. Almquist, P. Biswas, Appl. Catal. A 214 (2001) 259-271.

[11] N. Li, X. Lang, W. Ma, H. Ji, C. Chen, J. Zhao, Chem. Commun. 49 (2013) 50345036. 
[12] L. Cermenati, D. Dondi, M. Fagnoni, A. Albini, Tetrahedron 59 (2003) 6409-6414.

[13] S. Yurdakal, G. Palmisano, V. Loddo, O. Alagöz, V. Augugliaro, L. Palmisano, Green Chem. 11 (2009) 510-516.

[14] V. Balzani, A. Credi, M. Venturi, ChemSusChem 1 (2008) 26-58.

[15] N. Hoffmann, J. Photochem. Photobiol. C: Photochem. Rev. 9 (2008) 43-60.

[16] P. Cieśla, P. Kocot, P. Mytych, Z. Stasicka, J. Mol. Cat. A: Chem. 224 (2004) 17-33.

[17] S.I. Bokarev, O.S. Bokareva, O. Kühn, Coord. Chem. Rev. 304-305 (2015) 133-145.

[18] N. Hoffmann, J. Phys. Org. Chem. 28 (2015) 121-136.

[19] I. Balcioglu, I. Arslan, M.T. Sacan, Environ. Technol. 22 (2001) 813-822.

[20] A. Pace, S. Barreca, Curr. Org. Chem. 17 (2013) 3032-3041.

[21] G. Palmisano, S. Yurdakal, V. Augugliaro, V. Loddo, L. Palmisano, Adv. Synth. Catal. 349 (2007) 964-970.
[22] R. Marotta, I. Di Somma, D. Spasiano, R. Andreozzi, V. Caprio, J. Chem. Technol Biot. 88 (2013) 864-872.

[23] R. Marotta, I. Di Somma, D. Spasiano, R. Andreozzi, V. Caprio, Chem. Eng. J. 172 (2011) 243-249.

[24] W. Chen, F.N. Rein, R.C. Rocha, Angew. Chem. Int. Ed. 48 (2009) 9672-9675.

[25] D. Spasiano, R. Marotta, I. Di Somma, R. Andreozzi, V. Caprio, Photochem. Photobiol. Sci. 12 (2013) 1991-2000.

[26] D. Spasiano, R. Marotta, I. Gargano, I. Di Somma, G. Vitiello, G. D’Errico, R Andreozzi, Chem. Eng. J. 249 (2014) 130-142.

[27] R. Noyori, M. Aoki, K. Sato, Chem. Commun. (2003) 1977-1986.

[28] C. Meng, K. Yang, X. Fu, R. Yuan, ACS Catal. 5 (2015) 3760-3766.

[29] J. Sanz, J. Soria, I. Sobrados, S. Yurdakal, V. Augugliaro, J. Phys. Chem. C 116 (2012) 5110-5115.

[30] S. Yurdakal, B.S. Tek, O. Alagöz, V. Augugliaro, V. Loddo, G. Palmisano, L. Palmisano, ACS Sustainable Chem. Eng. 1 (2013) 456-461. 